\title{
$X R C C 1$ gene polymorphisms in a population sample and in women with a family history of breast cancer from Rio de Janeiro (Brazil)
}

\author{
Priscila Falagan-Lotsch ${ }^{1}$, Marina S. Rodrigues ${ }^{1}$, Viviane Esteves ${ }^{2}$, Roberto Vieira ${ }^{2}$, Luis C. Amendola ${ }^{2}$, \\ Dante Pagnoncelli ${ }^{2}$, Júlio C. Paixão ${ }^{3}$ and Claudia V. De Moura Gallo ${ }^{1}$ \\ ${ }^{1}$ Departamento de Biologia Celular e Genética, Instituto de Biologia Roberto Alcântara Gomes, \\ Universidade Estadual do Rio de Janeiro, Rio de Janeiro, RJ, Brazil. \\ ${ }^{2}$ Departamento de Ginecologia, Instituto Fernandes Figueira, Fundação Oswaldo Cruz, \\ Rio de Janeiro, RJ, Brazil. \\ ${ }^{3}$ Departamento de Biologia Molecular, Instituto Fernandes Figueira, Fundação Oswaldo Cruz, \\ Rio de Janeiro, RJ, Brazil.
}

\begin{abstract}
The X-ray repair cross-complementing Group1 (XRCC1) gene has been defined as essential in the base excision repair (BER) and single-strand break repair processes. This gene is highly polymorphic, and the most extensively studied genetic changes are in exon 6 (Arg194Trp) and in exon 10 (Arg399GIn). These changes, in conserved protein sites, may alter the base excision repair capacity, increasing the susceptibility to adverse health conditions, including cancer. In the present study, we estimated the frequencies of the XRCC1 gene polymorphisms Arg194Trp and Arg399Gln in healthy individuals and also in women at risk of breast cancer due to family history from Rio de Janeiro. The common genotypes in both positions (194 and 399) were the most frequent in this Brazilian sample. Although the 194Trp variant was overrepresented in women reporting familial cases of breast cancer, no statistically significant differences concerning genotype distribution or intragenic interactions were found between this group and the controls. Thus, in the population analyzed by us, variants Arg194Trp and Arg399GIn did not appear to have any impact on breast cancer susceptibility.
\end{abstract}

Key words: XRCCl gene polymorphisms, breast cancer susceptibility, Brazilian population.

Received: July 11, 2008; Accepted: October 6, 2008.

Rio de Janeiro is the Brazilian State with the highest number of breast cancer cases: 92.77 cases $/ 10^{5}$ women, according to INCA (2008) estimates. Many risk factors are involved in breast cancer, the genetic component being one of the most important affecting its frequency (Antoniou and Easton, 2006). Therefore, at the population level, breast cancer shows a high degree of familial aggregation, in which $50 \%$ of the cases are explained by genes mainly involved in maintaining genome integrity (Walsh and King, 2007). DNA damage plays a central role in carcinogenesis and, consequently, genes involved in DNA repair are considered key genes in cancer development. The $\mathrm{X}$-ray repair cross-complementing Group1 (XRCC1) gene has been defined as essential in the base excision repair (BER) and single-strand break repair processes (Brem and Hall, 2005). The importance of this gene is highlighted by the descrip-

Send correspondence to Cláudia Vitória de Moura Gallo. Departamento de Biologia Celular e Genética, Instituto de Biologia Roberto Alcântara Gomes, Universidade Estadual do Rio de Janeiro, Rua São Francisco Xavier 524, $2^{\circ}$ andar, 20550-013 Rio de Janeiro, RJ, Brazil. E-mail: claudia.gallo@pq.cnpq.br. tion of its null mutant mice, whose embryonic development is arrested (Tebbs et al., 1999). The XRCCl gene codes for a protein that is capable of interacting with different repair proteins. More than 60 validated single-nucleotide $X R C C 1$ polymorphisms are listed in the Ensembl database, of which the most extensively studied are the genetic changes in exon 6 (Arg194Trp) and in exon 10 (Arg399Gln). The frequency of variant 194Trp is very low in Caucasians and African Americans (5\%-11\%), while the frequency of variant $399 \mathrm{Gln}$ ranges from 32 to $48 \%$ in Caucasians (Hu et al., 2005). These changes in conserved protein sites may alter the base excision repair capacity, increasing the susceptibility to adverse health conditions, including cancer (Hung et al., 2005).

In the present study, we estimated the frequencies of Arg194Trp and Arg399Gln in the XRCC1 gene in healthy individuals and also in women at high risk of breast cancer due to family history (FH), from Rio de Janeiro, in order to analyze possible differences between these groups regarding the distribution of $X R C C 1$ variants. 
Peripheral blood samples were collected from 418 healthy individuals from the general population (population sample) undergoing routine medical tests at the Pedro Ernesto University Hospital, in the city of Rio de Janeiro, and from 104 women participating in the "Breast Cancer and Genetics Project - National DNA Bank" (BNDNA) of the Fernandes Figueira Institute-FIOCRUZ, located in the same city. This DNA bank contains genomic DNA from no consanguineous women who reported breast cancer in firstand/or second-degree relatives (women with a family history of breast cancer). The control group consisted of 240 individuals (72 men and 168 women) taken from the population sample who had no reported case of breast or ovary cancer in the family and were not affected by breast or any other type of cancer. All the study subjects were recruited between 1996 and 2001, and epidemiological data were obtained by standardized questionnaires. Based on phenotype characteristics, the individuals were classified into whites and non-whites (mulattoes and blacks). Written informed consent was obtained from each subject. This study was approved by the Ethics Committees of the Pedro Ernesto University Hospital and the Fernandes Figueira Institute. Genomic DNA was prepared from the blood samples by proteinase $\mathrm{K}$ digestion, according to standard methods (Sambrook et al., 1989). Genotyping of the XRCC1 polymorphisms was performed as described by Deligezer and Dalay (2004). Some randomly selected samples were genotyped by direct sequencing (ABI Prism Sequence Detection System - Applied Biosystems) to confirm the results. Chisquare or Fisher's exact test were applied to compare the different groups with regard to genotype frequencies. Statistical analysis was performed using the GraphPad Instat 3 software (GraphPad Software, San Diego, CA); the probability level (p) of less than 0.05 was used as significance criterion.

The characteristics of the study groups "Population Sample" $(\mathrm{n}=418)$, "Women with family history $(\mathrm{FH})$ of breast cancer" $(n=104)$, and "Controls" $(n=240)$ are presented in Table 1. The mean age of the Population Sample was $49.7 \pm 16.4$ years, and its ethnic composition was $51 \%$ whites and $46 \%$ non-whites. All of them were inhabitants of the metropolitan area of Rio de Janeiro for at least 6 months. The group of FH women was slightly younger than the controls (mean age: $44.4 \pm 13.1$ and $49.3 \pm 16.4$ years, respectively). A significant difference $(p<0.05)$ with respect to ethnicity was observed: the number of white individuals was higher in the $\mathrm{FH}$ women compared to controls. It is important to note that $57 \%$ of the women of the $\mathrm{FH}$ group reported at least one first-degree relative affected by breast cancer, about $60 \%$ of which were diagnosed before the age of 50. Five women with a family history of breast cancer had breast cancer themselves at the time of blood collection. The frequency of the XRCC1 polymorphism in the Population Sample is presented in Table 2, showing that the Arg/Arg genotypes in both positions (194 and 399)
Table 1 - Descriptive characteristics of the population sample, women with family history $(\mathrm{FH})$ of breast cancer and controls.

\begin{tabular}{lccc}
\hline Characteristics & $\begin{array}{c}\text { Population sample } \\
(\mathrm{n}=418)\end{array}$ & $\begin{array}{c}\text { Women with } \\
\mathrm{FH}(\mathrm{n}=104)\end{array}$ & $\begin{array}{c}\text { Control } \\
(\mathrm{n}=240)\end{array}$ \\
\hline Age (years) & $49.7 \pm 16.4$ & $44.4 \pm 13.1$ & $49.3 \pm 16.2$ \\
\hline Ethnicity, $\mathrm{n}(\%)$ & & & \\
\hline Whites & $214(51.0)$ & $65(62.0)$ & $122(51.0)$ \\
Non-whites & $190(46.0)$ & $35(34.0)$ & $118(49.0)$ \\
Missing data & $14(3.0)$ & $4(4.0)$ & 0 \\
\hline Classification by degree of affected relatives ${ }^{1}, \mathrm{n}(\%)$ \\
\hline \multicolumn{4}{c}{$59(57.0)$} \\
\multicolumn{5}{l}{ First } & $45(43.0)$ \\
\hline
\end{tabular}

${ }^{1}$ First-degree relative: at least one first-degree relative affected by breast cancer; second- degree: at least one second-degree relative affected by breast cancer and no affected first-degree relative.

were the most frequent. The homozygous 194Trp genotype is extremely rare and was detected in only two individuals. When this group was stratified by ethnicity (whites and non-whites), we observed that the heterozygous genotype Arg/Trp for codon 194 and the homozygous genotype Gln/Gln for codon 399 were more prevalent in whites compared to non-whites. However, these differences were not statistically significant. Analysis of a possible intragenic association between codon 194 and codon 399 alleles showed that the wild-type (Arg194/Arg399) and the combination of Arg 194 and 399Gln alleles were equally distributed in the Population Sample (43.5\% and 44.0\%, respectively). In this analysis, we did not observe any statistically significant difference between whites and non-whites (Table 3). In order to evaluate the possible contribution of the $X R C C 1$ polymorphisms to breast cancer susceptibility, we analyzed the genotype distribution in a group of women with an FH of breast cancer. Thus, the frequencies were determined in this particular group and compared with the genotype distribution observed in the controls. Since the frequency of $X R C C 1$ polymorphisms does not vary according to gender (male $x$ female: $p=0.80$ for codon $194 ; p=0.15$ for codon 399), the control group was composed of both men and women from the population sample with no previous cases of breast or ovary cancer in the family. The distribution of XRCC1 polymorphisms was similar in both groups, although women with an FH of breast cancer showed a higher percentage of genotypes presenting the Trip allele (Arg/Trp + Trp/Trp) than the controls (19.3\% and $13.3 \%$, respectively). This difference was more noticeable when we considered only women reporting at least one affected first-degree relative: $22 \%$ x $13.3 \%$ in controls. On the other hand, the Gln allele for codon 399 was more frequent in the control group. However, these differences were not statistically significant (Table 4). Women reporting only second-degree relatives affected by breast cancer showed a similar genotype distribution and allele frequen- 
Table 2 - Frequency of polymorphisms XRCC1-Arg194Trp and XRCC1-Arg399Gln in the population sample and distribution according to ethnicity.

\begin{tabular}{|c|c|c|c|c|}
\hline Genotype $X R C C 1^{1}$ & Population sample $(n=418) n(\%)$ & White $(n=214) n(\%)$ & Non-White $(\mathrm{n}=190) \mathrm{n}(\%)$ & $\mathrm{p}$-value $\mathrm{e}^{2}$ \\
\hline \multicolumn{5}{|l|}{ Arg194Trp } \\
\hline Arg/Arg & $366(87.6)$ & $182(85.0)$ & $170(89.5)$ & \\
\hline $\operatorname{Arg} / \operatorname{Trp}$ & $50(12.0)$ & $31(14.5)$ & $19(10.0)$ & \\
\hline $\operatorname{Trp} / \operatorname{Trp}$ & $2(0.5)$ & $1(0.5)$ & $1(0.5)$ & \\
\hline $\operatorname{Arg} / \operatorname{Trp}+\operatorname{Trp} / \operatorname{Trp}$ & $52(12.5)$ & $32(15.0)$ & $20(10.5)$ & 0.23 \\
\hline Trp-allele frequency & 0.07 & 0.08 & 0.06 & \\
\hline \multicolumn{5}{|l|}{ Arg399Gln } \\
\hline $\operatorname{Arg} / \operatorname{Arg}$ & $223(53.4)$ & $109(50.9)$ & $106(55.8)$ & \\
\hline $\operatorname{Arg} / \mathrm{Gln}$ & $159(38.0)$ & $82(38.3)$ & $73(38.4)$ & \\
\hline $\mathrm{Gln} / \mathrm{Gln}$ & $36(8.6)$ & $23(10.8)$ & $11(5.8)$ & 0.18 \\
\hline $\mathrm{Arg} / \mathrm{Gln}+\mathrm{Gln} / \mathrm{Gln}$ & $195(46.6)$ & $105(49.1)$ & $84(44.2)$ & \\
\hline Gln-allele frequency & 0.28 & 0.30 & 0.25 & \\
\hline
\end{tabular}

${ }^{1}$ Missing data - 14 (3.3\%) individuals of the population sample could not be classified according to ethnic group.

${ }^{2}$ Chi-square or Fisher's exact test.

Table 3 - Intragenic association of the $X R C C 1$ polymorphisms (Population sample).

\begin{tabular}{|c|c|c|c|c|c|}
\hline Exon 6 Codon 194 & Exon 10 Codon 399 & Population sample n (\%) & White $\mathrm{n}(\%)$ & Non-White $\mathrm{n}(\%)$ & $\mathrm{p}$-Value ${ }^{1}$ \\
\hline \multicolumn{6}{|c|}{ All wild-type genotypes } \\
\hline $\operatorname{Arg}$ & $\operatorname{Arg}$ & $182(43.5)$ & $84(39.3)$ & $90(47.4)$ & \\
\hline \multicolumn{6}{|c|}{ One variant polymorphism } \\
\hline $\operatorname{Trp}$ & $\operatorname{Arg}$ & $41(9.8)$ & $25(11.7)$ & $16(8.4)$ & 0.17 \\
\hline Arg & Gln & $184(44.0)$ & $98(45.8)$ & $80(42.1)$ & 0.24 \\
\hline \multicolumn{6}{|c|}{ Two variant polymorphisms } \\
\hline $\operatorname{Trp}$ & Gln & $11(2.7)$ & $7(3.2)$ & $4(2.1)$ & 0.36 \\
\hline
\end{tabular}

${ }^{1}$ Fisher's exact test (the wild-type genotypes were used as reference).

cies for both XRCC1 variants compared to the control group. In the ethnicity analysis, the distribution of polymorphisms Arg194Trp and Arg399Gln in women with FH and in controls was similar in whites and non-whites (whites: $\mathrm{p}=0.08$ for codon $194 ; \mathrm{p}=0.44$ for codon 399 ; non-whites: $p=1.00$ for codon 194; $p=0.34$ for codon 399). The intragenic association study did not show any statistically significant difference concerning the frequency of a particular genotype combination for both polymorphic variants when women with an affected first-degree relative and controls were compared (194Trp/Arg399: $p=0.49$; Arg194/399Gln: $\mathrm{p}=0.33 ; 194 \operatorname{Trp} / 399$ Gln: $\mathrm{p}=0.26$. Reference: Arg194/Arg399). All genotype distributions of the $X R C C 1$ gene were in Hardy-Weinberg equilibrium.

The XRCC1 protein is considered an essential part of both the single-strand break repair and the base excision repair systems (Cappelli et al., 1997). Here, we studied two XRCC1 polymorphisms: Arg194Trp, located in exon 6, and Arg399Gln, located in exon 10. Both substitutions produced structural changes in the protein molecule, probably altering its biological activity and consequently affecting the DNA repair efficiency. These observations led us to realize the importance of determining the distribution of these genetic variants in our population. Brazil has a large territory and the differences in colonization among different geographical regions resulted in different levels of miscegenation (Alves-Silva et al., 2000). So far, four papers have described the XRCC1 genotype distribution in Brazilian populations, all of them from the State of São Paulo (Rossit et al., 2002; Duarte et al., 2005; Dufloth et al., 2005; Canalle et al., 2006). The distribution of both polymorphisms found by us in a population sample from Rio de Janeiro was similar to that found in São Paulo, the wildtype genotypes being the most frequent. Concerning ethnicity, the allele frequency for the 194Trp variant in Eurodescendents (whites) from Rio de Janeiro was 0.08 and in Afro-descendents (non-whites) 0.06 (Table 2). These results are in agreement with those observed in American and European Caucasians (0.05-0.09) and in African Americans (0.05-0.11) (Lunn et al., 1999; David-Beabes and London, 2001; Smith et al., 2003; Hu et al., 2005; Pachkowski et al., 2006). The frequency of the 399Gln 
Table 4 - Allele and genotype frequencies of polymorphisms XRCC1-Arg194Trp and XRCC1-Arg399Gln in women reporting a family history (FH) of breast cancer in first-degree relatives and controls.

\begin{tabular}{lccc}
\hline Genotype $X R C C 1$ & Women with FH in first-degree relatives n $(\%)$ & Controls n (\%) & OR $(95 \% \mathrm{CI})^{1}$ \\
\hline Arg194Trp & & & \\
Arg/Arg & $46(78.0)$ & $208(86.6)$ & 1.0 (reference) \\
Arg/Trp & $12(20.3)$ & $32(13.4)$ & $1.70(0.81-3.54)$ \\
Trp/Trp & $1(1.7)$ & 0 & ND $^{2}$ \\
Arg/Trp + Trp/Trp & $13(22.0)$ & $32(13.3)$ & $1.84(0.89-3.77)$ \\
Trp allele frequency & 0.12 & 0.07 & \\
\hline Arg399Gln & & & \\
Arg/Arg & $33(55.9)$ & $120(48.8)$ & $1.0($ reference $)$ \\
Arg/Gln & $25(42.4)$ & $103(41.9)$ & $0.88(0.49-1.58)$ \\
Gln/Gln & $1(1.7)$ & $23(9.3)$ & $0.16(0.02-1.22)$ \\
Arg/Gln + Gln/Gln & $26(44.1)$ & $126(51.2)$ & $0.75(0.42-1.33)$ \\
Gln allele frequency & 0.23 & 0.30 & \\
\hline
\end{tabular}

${ }^{1}$ Fisher's exact test.

${ }^{2} \mathrm{ND}$ not determined due to small sample size in the category.

variant allele was of 0.30 in Brazilians of European descent, quite similar to the frequencies reported for American Caucasians (0.32-0.37) and European Caucasians (0.32-0.48) (Lunn et al., 1999; David-Beabes and London, 2001; Matullo et al., 2001; Duell et al., 2002; Smith et al., 2003; Hu et al., 2005; Pachkowski et al., 2006). In the Brazilians of African descent, the frequency of the 399 Gln allele was 0.25 , about the same (0.27) as observed by Canalle et al. (2006) for Afro-descendents from São Paulo (Brazil), but higher than that observed in African Americans (0.14-0.18) (Lunn et al., 1999; David-Beabes and London, 2001; Duell et al., 2002; Hu et al., 2005; Pachkowski et al., 2006). The intragenic association analysis showed that the most frequent combinations were the wild-type Arg194/Arg399 and the genotype with one variant Arg194/399Gln (43.5\% and 44.0\%, respectively), revealing the high frequency of the Gln allele in the Brazilian population. It remains, however, to be clarified which are the reasons why the State of Rio de Janeiro is the one with the highest number of breast cancer cases in Brazil. Family aggregation of this disease is also largely observed, which led us to search for clues about genetic susceptibility. Although hereditary breast cancer is commonly associated with high-penetrance genes such as BRCA1/2 and TP53 (Walsh et al., 2006), a clear risk genotype for the most part of the breast cancer families has not yet been described (Antoniou and Easton, 2006). In an approach distinct from the classical case-control association studies, we compared the distribution of the most studied variants of the $\mathrm{XRCCl}$ gene in women reporting FH of breast cancer with the distribution in individuals without reported breast cancer cases in the family (controls). No statistical differences were observed in the genotype distributions or in the intragenic interactions of polymorphisms Arg194Trp and Arg399Gln. So, according to our data, these XRCC1 gene variants do not appear to have any impact on breast cancer susceptibility in the analyzed population. To elucidate the role of $X R C C 1$ variants and cancer risk, several casecontrol studies have been conducted, but the results are inconsistent. Two meta-analysis studies described the 194Trp variant as being related to a decrease in cancer risk (Goode et al., 2002; Hu et al., 2005), but Chacko et al. (2005) observed an association between allele 194Trp and the risk of breast cancer in women from India. However, a recent meta-analysis performed with a large number of cases from the United States (Zhang et al., 2006) did not find any relation between the presence of either the XRCC1 Arg194Trp or the Arg399Gln polymorphisms, among other DNA repair genes, and risk of breast cancer. Repair genes are unequivocally important in the process of breast cancer susceptibility but, as several repair systems may superpose and act together, a clear picture in case-control studies is very difficult to achieve. In spite of our limited sample size, we found the same trend described in previous studies on breast cancer patients with an FH (Smith et al., 2003; Dufloth et al., 2005; Costa et al., 2007). Further studies with larger samples are needed to elucidate the role of these $X R C C 1$ gene variants in the genetic susceptibility to breast cancer.

\section{Acknowledgments}

The authors thank the patients and the collaborative participation of the families in this study. We also thank Nell Gonçalves for preparing the genomic DNA. The DNA sequencing of this study was supported by "Plataforma Genômica-Sequenciamento de DNA/PDTISFIOCRUZ". PFL was the recipient of a fellowship from CAPES/Brazil 


\section{References}

Alves-Silva J, da Silva Santos M, Guimaraes PE, Ferreira AC, Bandelt HJ, Pena SD and Prado VF (2000) The ancestry of Brazilian mtDNA lineages. Am J Hum Genet 67:444-461. Erratum in (2000), Am J Hum Genet Sep 67:775.

Antoniou AC and Easton DF (2006) Models of genetic susceptibility to breast cancer. Oncogene 25:5898-5905.

Brem R and Hall J (2005) XRCC1 is required for DNA single-strand break repair in human cells. Nucleic Acids Res 33:2512-2520.

Canalle R, da Silva S, Andrade V, Scrideli CA, de Paula Queiroz RG and Tone LG (2006) Polymorphisms in the thymidylate synthase promoter and the DNA repair genes XRCC1 and XPD in a Brazilian population. Environ Mol Mutagen 47:725-732.

Cappelli E, Taylor R, Cevasco M, Abbondandolo A, Caldecott K and Frosina G (1997) Involvement of XRCC1 and DNA ligase III gene products in DNA base excision repair. J Biol Chem 272:23970-23975.

Chacko P, Rajan B, Joseph T, Mathew BS and Pillai MR (2005) Polymorphisms in DNA repair gene XRCC1 and increased genetic susceptibility to breast cancer. Breast Cancer Res Treat 89:15-21.

Costa W, Pinto D, Pereira D, Rodrigues H, Cameselle-Teijeiro J, Medeiros R and Schmitt F (2007) DNA repair polymorphisms might contribute differentially on familial and sporadic breast cancer susceptibility: A study on a Portuguese population. Breast Cancer Res Treat 103:209-217.

David-Beabes GL and London SJ (2001) Genetic polymorphism of XRCC1 and lung cancer risk among African-Americans and Caucasians. Lung Cancer 34:333-339.

Deligezer U and Dalay N (2004) Association of the XRCC1 gene polymorphisms with cancer risk in Turkish breast cancer patients. Exp Mol Med 36:572-575.

Duarte MC, Colombo J, Rossit AR and Silva AE (2005) Polymorphisms of the DNA repair genes XRCC1 and XRCC3 in a Brazilian population. Genet Mol Biol 28:397-401.

Duell EJ, Holly EA, Bracci PM, Wiencke JK and Kelsey KT (2002) A population-based study of the Arg399Gln polymorphism in X-ray repair cross-complementing group 1 (XRCC1) and risk of pancreatic adenocarcinomas. Cancer Res 62:4630-4636.

Dufloth RM, Costa S, Schmitt F and Zeferino LC (2005) DNA repair gene polymorphisms and susceptibility to familial breast cancer in a group of patients from Campinas, Brazil. Genet Mol Res 4:771-782.

Goode EL, Ulrich CM and Potter JD (2002) Polymorphisms in DNA repair genes and associations with cancer risk. Cancer Epidemiol Biomarkers Prev 11:1513-1530.

Hu Z, Ma H, Chen F, Wei Q and Shen H (2005) XRCC1 polymorphisms and cancer risk: A meta-analysis of 38 case-control studies. Cancer Epidemiol Biomarkers Prev 14:1810-1818.
Hung RJ, Hall J, Brennan P and Boffetta P (2005) Genetic polymorphisms in the base excision repair pathway and cancer risk: A HuGE review. Am J Epidemiol 162:925-942.

Lunn RM, Langlois RG, Hsieh LL, Thompson CL and Bell DA (1999) XRCC1 polymorphisms: Effects on aflatoxin B1DNA adducts and glycophorin A variant frequency. Cancer Res 59:2557-2561.

Matullo G, Guarrera S, Carturan S, Peluso M, Malaveille C, Davico L, Piazza A and Vineis P (2001) DNA repair gene polymorphisms, bulky DNA adducts in white blood cells and bladder cancer in a case-control study. Int $\mathrm{J}$ Cancer 92:562-567.

Pachkowski BF, Winkel S, Kubota Y, Swenberg JA, Millikan RC and Nakamura J (2006) XRCC1 genotype and breast cancer: Functional studies and epidemiologic data show interactions between XRCC1 codon 280 His and smoking. Cancer Res 66:2860-2868.

Rossit AR, Cabral IR, Hackel C, da Silva R, Froes ND and Abdel-Rahman SZ (2002) Polymorphisms in the DNA repair gene XRCC1 and susceptibility to alcoholic liver cirrhosis in older Southeastern Brazilians. Cancer Lett 180:173-182.

Sambrook J, Fritsch EF and Maniatis T (1989) Molecular Cloning: A Laboratory Manual. 2nd edition. Cold Spring Habour Laboratory Press, New York.

Smith TR, Miller MS, Lohman K, Lange EM, Case LD, Mohrenweiser HW and Hu JJ (2003) Polymorphisms of XRCC1 and $\mathrm{XRCC} 3$ genes and susceptibility to breast cancer. Cancer Lett 190:183-190.

Tebbs RS, Flannery ML, Meneses JJ, Hartmann A, Tucker JD, Thompson LH, Cleaver JE and Pedersen RA (1999) Requirement for the XRCC1 DNA base excision repair gene during early mouse development. Dev Biol 208:513-529.

Walsh T and King MC (2007) Ten genes for inherited breast cancer. Cancer Cell 11:103-105.

Walsh T, Casadei S, Coats KH, Swisher E, Stray SM, Higgins J, Roach KC, Mandell J, Lee MK, Ciernikova S et al. (2006) Spectrum of mutations in BRCA1, BRCA2, CHEK2, and TP53 in families at high risk of breast cancer. JAMA 295:1379-1388.

Zhang Y, Newcomb PA, Egan KM, Titus-Ernstoff L, Chanock S, Welch R, Brinton LA, Lissowska J, Bardin-Mikolajczak A, Peplonska B et al. (2006) Genetic polymorphisms in baseexcision repair pathway genes and risk of breast cancer. Cancer Epidemiol Biomarkers Prev 15:353-358.

\section{Internet Resources}

INCA (Instituto Nacional do Câncer), Estimativa 2008: incidência de câncer no Brasil, Rio de Janeiro. http://www.inca.gov.br/ estimativa/2008 (June 1, 2008)

Associate Editor: Francisco Mauro Salzano

License information: This is an open-access article distributed under the terms of the Creative Commons Attribution License, which permits unrestricted use, distribution, and reproduction in any medium, provided the original work is properly cited. 